\title{
Separation of Fe(II) by the DEMI and TEMPO Oxidized Cellulose
}

\author{
Michaela Filipi, Miloslav Milichovsky \\ Department of Wood, Pulp and Paper, Faculty of Chemical Technology, University of Pardubice, Pardubice, \\ Czech Republic \\ Email: michaela.filipi@upce.cz
}

Received 26 May 2015; accepted 11 August 2015; published 14 August 2015

Copyright $@ 2015$ by authors and Scientific Research Publishing Inc.

This work is licensed under the Creative Commons Attribution International License (CC BY).

http://creativecommons.org/licenses/by/4.0/

(c) (i)

\begin{abstract}
The description of some adsorption properties and behaviour of oxycellulose with $\mathrm{Fe}^{2+}$ ions is presented. Filter media from oxycelluloses materials have enormous sorption activity. There is described a sorption mechanism of poly 1,4- $\beta$-D anhydroglucuronic acid (PAGA). Utilisation of UV-VIS spectroscopy is shown on the adsorption process of optimalisation of oxycelluloses application. Supporting influence is demonstrated on the adsorption isotherms of $\mathrm{Fe}^{2+}$ ions in the competitive environment of $\mathrm{NaCl}, \mathrm{MgCl}_{2}$.
\end{abstract}

\section{Keywords}

\section{Natural Cellulose, Filtration, UV-VIS Spectrofotometry}

\section{Introduction}

Water filtration was long viewed as merely a mechanical process [1]. To function as a filter, the filter media must allow the fluid, commonly water or aqueous systems, flows through, while holding back particulate contaminants [1].

Adsorption characteristics of polysaccharides, cellulose and its derivatives including oxycellulose in relation to cations, particularly [2] heavy metals, have drawn more and more attention recently. Their knowledge is important in the field of purification and treatment of water as well as from the medical point of view, because especially ferrum plays an important role in metabolism of animals and humans [3]-[5].

Natural oxycelluloses in wet state are heterogeneous highly hydrated substances (hydrogels of various space concentrations). In its purest form they have the same chemical composition, but different sizes of molecules and representations of $\mathrm{COOH}$ groups organized into complex of supramolecular structure. Moreover, oxycellulose prepared from natural cellulose keeps to a short extent also its hypermolecular structure having a complex 
morphology of their cell-walls [3].

The whole adsorption process is getting complex indeed, as several parallel reactions are taking place [6] [7]:

$>$ an adsorption itself, which is the reaction of the superficial groups with the sorbing substances in the interface of the highly hydrated cellulose fibres;

$>$ an reaction of the sorbing substances with the molecules and microgel dissolved particles of cellulose directly in the solution.

These competing interactions complicate the whole adsorption process and influence of its course.

The entire adsorption process depends on the composition and properties of the used cellulose. For example, oxycellulose contains high amount of high-molecular PAGA of high DP and with high amount of COOH groups which are difficult to release into aqueous solution. The adsorption isotherm is then of a sigmoidal form, it is high and it has short initial phase. On the contrary, oxycellulose with the same composition and level of substitution but with a low DP with high polydispersity characterized by high solubility has longer initial phase and smaller both the adsorption capacity and slope of the adsorption curve. This implies that at comparable conditions, which means affinity and concentration of molecules of sorbent at its interface with the solution and in the solution itself, the reactions in the solution will be preferred because due to stirring these reactions take place easier and more uniformly. Only after their depletion a proper adsorption process will be followed. The slope of the true adsorption isotherm depends on the solubility of oxycellulose particles which have different affinity towards the molecules and hydrated nano-particles of sorbing substances. If the particles with high affinity towards the sorbing substances are released into the solution then the slope of the adsorption isotherm will be slight and vice-versa [3].

However, it is more complicated with the height of the adsorption isotherm which defines the adsorption capacity of the sorbent. It depends not only on the affinity of the sorbent towards the molecules and nano-particles of the sorbing substances but it is mainly defined by the concentration and accessibility of adsorption centres [3]. It is higher at more spongy structures developed by an erosive process of leaching of originally compact hydrogel substance of cellulose in amorphous and gradually even crystallinic oriented areas and their ability to induce their following interactions leading to superficial flocculation [8]. Hence, if fractions with high affinity towards the sorbing substances are dissolved from the oxycelullose whereas the remaning available sorption centres will be either of high concentration or will have high competence to provoke superficial flocculation of nano-particles of these ones then the adsorption capacity of oxycellulose will be high. Vice-versa, if the major part of all the affinity fractions among them the fractions with comparable or slightly lower affinity towards the adsorbable molecules and nano-particles, particularly released from the oxycellulose into the solution and only small amount of available fractions with the high affinity remains then the true adsorption isotherm will have steep slope but low adsorption capacity. Logically, all these processes are influenced by presence of other ions, i.e. by composition and concentration of electrolyte environment.

\section{TEMPO Oxidation}

Catalytic oxidation using water-soluble and stabile nitroxyl radicals such as 2,2',6,6'-tetramethylpiperidine1-oxyl (TEMPO) under aqueous conditions has become one of the interesting ways for introduction of functional groups in cellulose [9]. Oxidative conversion of cellulose by the system TEMPO/sodium hypochlorite/ potassium bromide was first reported in 1994 [10] and has been the subject of several studies since then [11][13]. The TEMPO-mediated oxidation was described to cause selective oxidation at C-6 of the anhydroglucose units to carboxyl groups via the intermediate carbonyl stage, finally producing water-soluble polyglucuronic acids. The nitroxyl radical affects the oxidation from the alcohol to the carbonyl oxidation state, while the hypobromite generated in situ from hypochlorite and bromide performs the further oxidation of the carbonyl to the carboxylic acid.

\section{Materials and Methods}

\subsection{Reagent and Chemicals}

Oxycelluloses were oxidised by nitrate oxidants $\left(\mathrm{HNO}_{3}\right.$ or $\left.\mathrm{N}_{2} \mathrm{O}_{4}\right)$ in Synthesia, Pardubice-Semtin. Two sorts of oxycelluloses were applied in the experiments.

$>$ Oxycellulose DEMI: 19\% COOH groups (oxycellulose prepared in de-mineralized water environment).

$>$ Oxycellulose TEMPO: 3.5\% COOH groups, DP 17.1, dissolved component 65\% (prepared by TEMPO 
oxidadion).

\subsection{Preparation of Oxycellulose Suspension}

DEMI and TEMPO oxycellulose suspension was prepared by weighing out of $20 \mathrm{~g}$ of air dried oxycellulose followed by its dissolution in 1 litre of distilled water. In order to reach better homogenization of fibrous suspension, the oxycellulose DEMI and TEMPO were refined to reach better homogenization of fibrous suspension.

Temperature of refined suspensions of oxycellulose has been controlled in order not to achieve $70^{\circ} \mathrm{C}$ as the higher temperature leads to oxycellulose degradation.

As the oxycellulose dissolves in water, it is neccessary to keep prepared suspension at least half an hour to reach equilibrium and to avoid further dissolution. Thus, the dissolution changes the consistence of fibrous suspension. The composition and structure of used oxycellulose were determined by method of UV-VIS spectroscopy [14].

\subsection{Adsorption Experiments}

While stirring continuously using vitreous stirrer (300 revolutions per minute), $50 \mathrm{ml}$ of oxycellulose suspension was withdrawn and $10 \mathrm{ml}$ of ions solution from each calibration solution was added to it [3]. The mixture was intensively stirred up with vitreous stirrer for the period of 5, 10, 15 and 20 minutes at the room temperature, e.g. $20^{\circ} \mathrm{C} \pm 1^{\circ} \mathrm{C}$. The prepared suspension was filtered through a filter $\mathrm{S}_{2}$ and dried at the temperature of $70^{\circ} \mathrm{C}$. The amount of ions in the filtrate was then determined by the means of spectrophotometry.

\subsection{Spectrophotometric Determination of Ferrum}

After reduction of $\mathrm{Fe}^{3+}$ to $\mathrm{Fe}^{2+}$ by hydroxylamine hydrochloride the $\mathrm{Fe}^{2+}$ ions create complex ions with 1,10fenathrolin (fen)-Fe(fen) $)_{3}$ (feroin) of red colour [10]. The colour is almost permanently stabile and its intensity does not depend on the $\mathrm{pH}$ within the range of $2-9$ [14] $\left(\varepsilon_{512 \mathrm{~nm}}=11000 \mathrm{dm}^{3} \cdot \mathrm{mol}^{-1} \cdot \mathrm{cm}^{-1}\right)$. The determination is interferred with a large number of ions producing either precipitates or colour adducts with the basic components of the system [9].

The calibration graph was set up by adding of 16, 18, 20, 22, 24, 26, 28 and $30 \mathrm{ml}$ of standard solution of $\mathrm{Fe}^{2+}$ with a pipette into $50 \mathrm{ml}$ graduated flask. The $\mathrm{pH}$ of the solution was adjusted by adding of $6.5 \mathrm{ml}$ of $\mathrm{CH}_{3} \mathrm{COONa}, 3.5 \mathrm{ml} \mathrm{CH} \mathrm{COOH}_{3} 2 \mathrm{ml}$ hydroxylamine. Also $5 \mathrm{ml}$ of the solution of 1,10-phenanthroline was added. $1 \mathrm{ml}$ of the solution thus contained $39.4 \mu \mathrm{g} \mathrm{Fe} \mathrm{[10].} \mathrm{The} \mathrm{measurement} \mathrm{is} \mathrm{performed} \mathrm{at} \mathrm{the} \mathrm{wavelength} \mathrm{of}$ $512 \mathrm{~nm}[9]$ against the reference solution (a solution of all chemicals without $\mathrm{Fe}^{2+}$ ).

\section{Results}

Sorption filtration is a separation process prompting the oxycelluloses to offer new levels of performance in nanotechnology [1]. Generally, the filtration processes are controlled by two mechanisms as follows [1]:

$>$ By mechanical capture of separed particles;

$>$ By sorption forces between ineracting particles, molecules etc. and walls of pores.

\subsection{Adsorption of $\mathrm{Fe}^{2+}$ in Form of Ferroin on Oxycelluloses in the Distilled Water}

Received results of adsorption experiments with $\mathrm{Fe}^{2+}$ in form of ferroin on oxycelluloses in the distilled water are illustrated in Figure 1 and Figure 2. As it results from figures, summarising all of the adsorption isotherms of feroin iron on oxycellulose at 5, 10, 15, 20 minutes all these isotherms are shaped sigmoidal varying in size, elongation of the initial phase and slope. Practically, for reaction times higher than 5 minutes all the adsorption isotherms are similar and time independent.

Surprisingly, as resulted by comparison the Figure 1 and Figure 2, the oxycellulose with higher content of $\mathrm{COOH}$ groups has lower adsorption capacity than oxycelllulose of lower $\mathrm{COOH}$ content. It is evident; the initial phase of the adsorption isotherm has nothing in common with adsorption but is evoked by the reaction of the soluble oxycellulose forms with the sorbing substances-in this case represented by $\mathrm{Fe}^{2+}$ ions, as these forms tend to have the highest affinity towards these ones. It is understandable as molecules and supramolecular soluble structures (hydrogel micro-particles) with high content of $\mathrm{COOH}$ groups have the highest affinity towards 


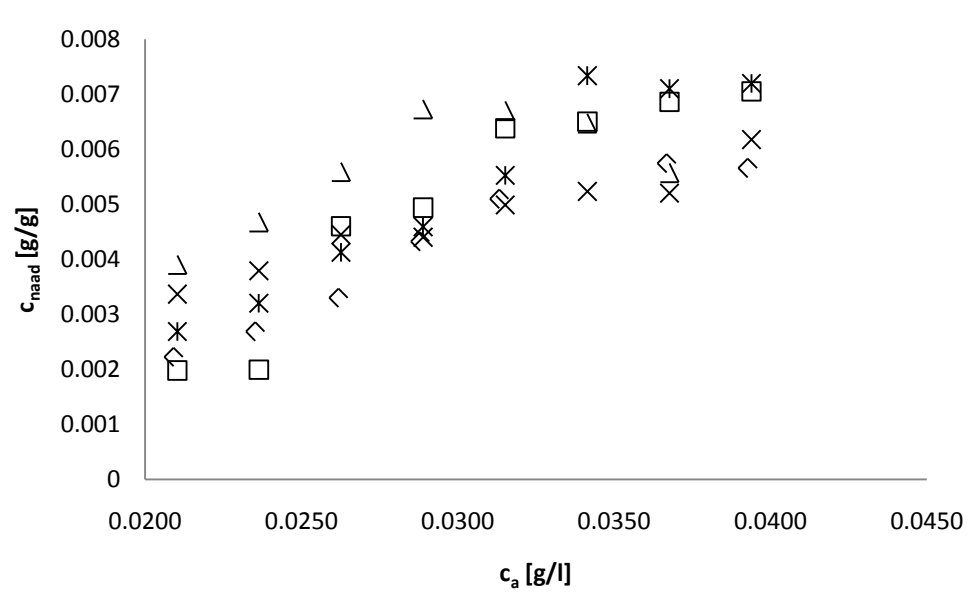

Figure 1. Time dependence of sorption isoterms of $\mathrm{Fe}^{2+}$ ions at suspensions of TEMPO oxycelullose (3.5\% $\mathrm{COOH}$ groups) in distilled water. $\diamond: 5$ minutes, $\square: 10$ minutes, $\Delta$ : 15 minutes, $\dot{\mathrm{x}}$ : 20 minutes, * $: 30$ minutes.

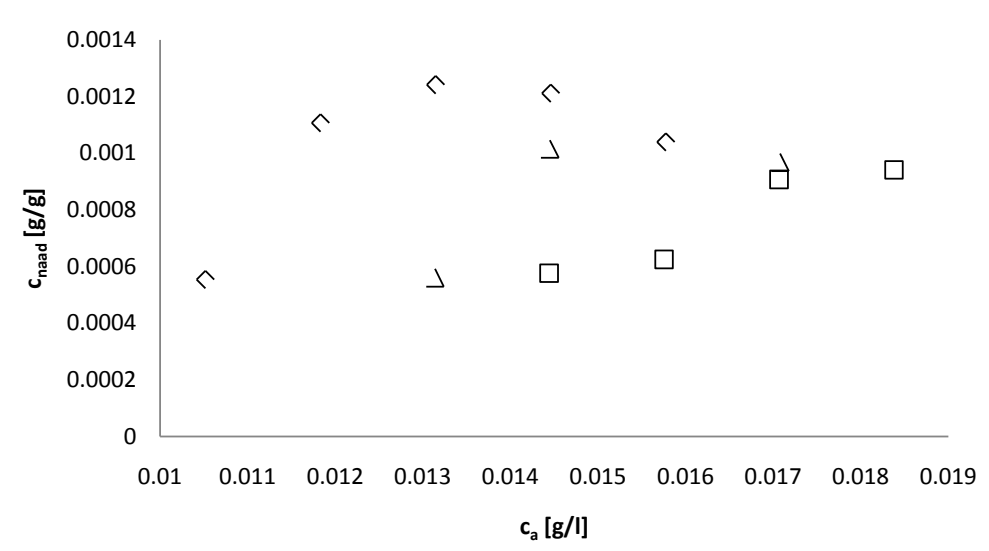

Figure 2. Time dependence of sorption isoterms of $\mathrm{Fe}^{2+}$ ions at suspensions of DEMI oxycelullose (19\% COOH groups) in distilled water. $\diamond: 5$ minutes, $\square: 15$ minutes, $\Delta: 20$ minutes.

$\mathrm{Fe}^{2+}$. The high content of $\mathrm{COOH}$ groups is responsible for their easy solubility and release from the fibrous cellulose structures into the aqueous environment.

\subsection{Adsorption of $\mathrm{Fe}^{2+}$ on Oxycelluloses in Mixture with Other Substances}

This behaviour was studied in the mixture modeled by the solution of $\mathrm{NaCl}, \mathrm{MgCl}_{2}, \mathrm{CaCO}_{3}$ and $\mathrm{Fe}^{2+}$ in the ferroin form. The results of this competitive adsorption on oxycelluloses are presented in Figure 3 and Figure 4. The typical feature of all the isotherms is that they do not start from zero equilibrium level of supernatant but they are markedly shifted towards higher concentrations even though higher adsorption effects (approx. two times) are observed in comparison with distilled water. This fact practically indicates that on the one hand a sorption capacity of cellulose and namely oxycelluloses will increase in the mixture with other competitive ions, on the other hand a considerable amount of $\mathrm{Fe}^{2+}$ ions will remain in the solution at its low concentration. Apparently, it seems to be the common manifestation of sorption process in the competitive environment. The present ions support adsorption-most probably the analogy of superficial aggregation (surface flocculation) evoked by the presence of foreign substances [7].

Adsorption behaviour of colloidal particles and metal ions is well described by use of Langmuir Isoterms [10] [15]. It is logical that uptake of monovalent cations are much lower than of divalent cations [9]. Affinity of $\mathrm{Na}^{+}$ to oxycellulose is nearly zero in presence of divalent cations. However, an even more complication situation arises in more diluted solutions (concentration < approximately $10^{-4}$ to $10^{-5} \mathrm{~mol} / \mathrm{l}$ ) in admixture with other 


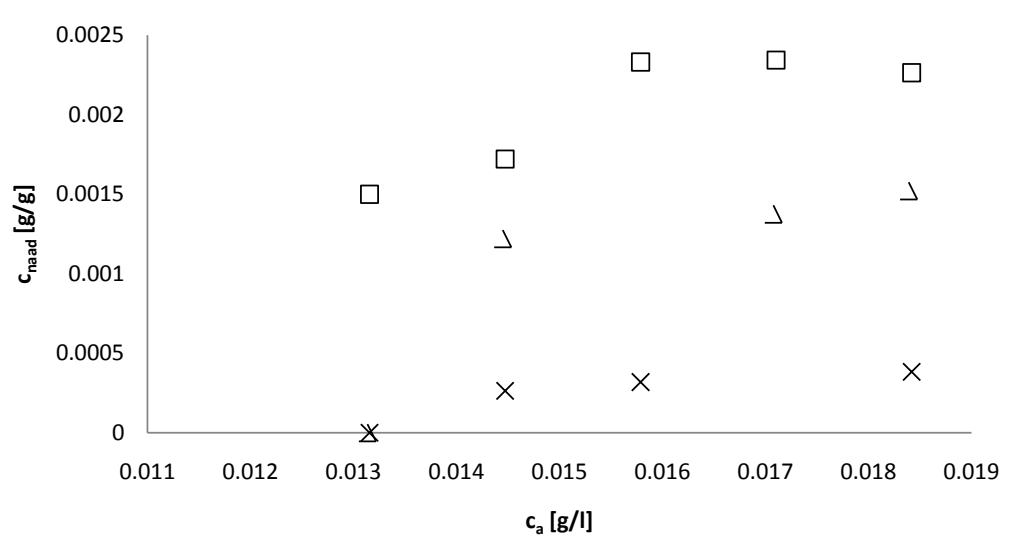

Figure 3. Time dependence of sorption isoterms of $\mathrm{Fe}^{2+}$ ions at suspensions of DEMI oxycelullose (19\% COOH groups) in the competitive environment of $\mathrm{NaCl} / \mathrm{MgCl}_{2} / \mathrm{CaCO}_{3} . \Delta$ : 10 minutes, $\square: 15$ minutes, $\dot{\mathrm{x}}$ : 30 minutes.

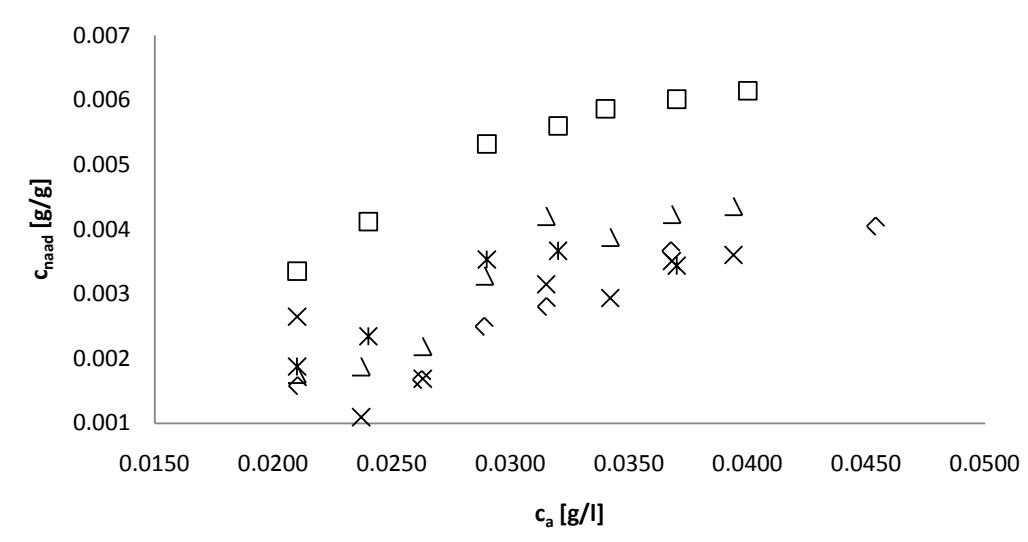

Figure 4. Time dependence of sorption isoterms of $\mathrm{Fe}^{2+}$ ions at suspensions of TEMPO oxycelullose (3.5\% COOH groups in the competitive environment of $\mathrm{NaCl} / \mathrm{MgCl}_{2} / \mathrm{CaCO}_{3} . \diamond: 5$ minutes, $\square: 10$ minutes, $\Delta: 15$ minutes, $\dot{\mathrm{x}}: 20$ minutes, *: 30 minutes.

substances especially with the colloid activity as Fe(II) or Fe(III) [1]. These competing interactions complicate the overall adsorption process and influence its final course. The sorption isotherm displays then a sigmoidal shape possessing a longer initial phase followed by a smaller slope and consequent a smaller adsorption capacity.

\section{Discussion}

The initial phase of the adsorption isotherm has nothing in common with adsorption but this is provoked by the reaction of the soluble oxycellulose forms with the sorbing substances. The slope of the adsorption isotherm in its inflexion point is given by the capacity of the sorbent and the affinity of the sorbing substance. The initial linear phase of these isotherms changes with the used oxycelluloses. When we compare the characteristics of the oxycelluloses, we can find out that the length of the initial phase is connected with the solubility of the used cellulose. The initial part of the adsorption isotherm has no connection with the adsorption itself but it is caused by the reaction of soluble forms of cellulose with the sorbing substances for those have the highest affinity.

The shape and the initial phase of the adsorption isotherm were different for ions in the distilled water and in the competitive environment of $\mathrm{NaCl}, \mathrm{MgCl}_{2}$. The adsorption isotherms for ions in the competitive environment of $\mathrm{NaCl}, \mathrm{MgCl}_{2}$ were moved to higher values than adsorption isotherm for ions in distilled water.

\section{Acknowledgements}

Research was co-financed by the European Social Fund and the state budget of the Czech Republic within the 
project VEPA—Science for paper artefacts, Reg. No. CZ.1.07/2.3.00/20.0236.

\section{References}

[1] Milichovsky, M., Češek, B., Filipi, M. and Gojny, J. (2014) Cellulosic Sorption Filter Materials with Surface Flocculation Activity-A Hopeful Anticipation of Water Purification. Journal of Water Resource and Protection, 63, 165-176. http://dx.doi.org/10.4236/jwarp.2014.63022

[2] Burke, A., Yilmaz, E. and Hasirci, N. (2000) Evaluation of Chitosan as a Potential MedicalIron (III) Ion Adsorbent. Turkish Journal of Medical Sciences, 30, 341-348.

http://journals.tubitak.gov.tr/medical/issues/sag-00-30-4/sag-30-4-5-9905-11.pdf

[3] Filipi, M. and Milichovský, M. (2008) Adsorption Characteristic of Oxycellulose in a Competitive Environment with Other Substance. Adsorption Science \& Technology, 26, 545-561. http://dx.doi.org/10.1260/0263-6174.26.7.545

[4] Saliba, R., Gauthier, H., Gauthier, R. and Petit-Ramel, M. (2002) The Use of Amidoximated Cellulose for the Removal of Metal Ions and Dyes from Waste Waters. Celulose, 9, 183-191. http://dx.doi.org/10.1023/A:1020117032406

[5] Yurkshtovich, N.K., Golub, N.V., Kaputskii, F.N., Yurkshtovich, T.L. and Kosterova, R.I. (2004) Properties of Monocarboxy Cellulose Containing Sorbed Fe(III), Al(III), and Cr(III) Cations. Russian Journal of Applied Chemistry, 77, 901-904. http://dx.doi.org/10.1023/B:RJAC.0000044113.64944.24

[6] Milichovsky, M. (2002) HISA Congress 2002. Prague Czech Republic.

[7] Milichovsky, M. and Češek, Br. (2002) Surface Flocculation as a New Tool for Controlling Adsorption Processe. Adsorption Science \& Technology, 20, 883-896. http://dx.doi.org/10.1260/02636170260555796

[8] Milichovsky, M. (1990) A New Concept of Chemistry Refining Processes. Tappi Journal, 73, 221-232.

[9] Saito, T., Shibata, I., Isogaia, A., Suguri, N. and Sumikawa, N. (2005) Distribution of Carboxylate Groups Introduced into Cotton Linters by the TEMPO-Mediated Oxidation. Carbohydrate Polymers, 61, 414-419. http://dx.doi.org/10.1016/j.carbpol.2005.05.014

[10] Milichovsky, M. and Milichovska, Sv. (2008) Characterization of Oxidized Cellulose by Using UV-VIS Spectroscopy. Journal of Applied Polymer Science, 107, 2045-2052. http://dx.doi.org/10.1002/app.27232

[11] Isogai, A. and Kato, Y. (1998) Preparation of Polyuronic Acid from Cellulose by TEMPO-Mediated Oxidation. Cellulose, 5, 153-164. http://dx.doi.org/10.1023/A:1009208603673

[12] de Nooy, A.E.J., Pagliaro, M., van Bekkum, H. and Besemer, A.C. (1997) Autocatalytic Oxidation of Primary Hydroxyl Functions in Glucans with Nitrogen Oxides. Carbohydrate Research, 304, 117-123. http://dx.doi.org/10.1016/S0008-6215(97)10004-0

[13] de Nooy, A.E.J., Besemer, A.C. and van Bekkum, H. (1994) Highly Selective Tempo Mediated Oxidation of Primary Alcohol Groups in Polysaccharides. Recueil des Travaux Chimiques des Pays-Bas, 113, 165-166. http://dx.doi.org/10.1002/recl.19941130307

[14] Malát, M. (1973) Absorbtion Inogranic Photometry. Academia Prague Czechoslovakia.

[15] Foglarova, M., Prokop, J. and Milichovsky, M. (2009) Oxidized Cellulose: An Application in the Form of Sorption Filter Materials. Journal of Applied Polymer Science, 112, 669-678. http://dx.doi.org/10.1002/app.29465 